\title{
Nanoscale
}

Cite this: Nanoscale, 2013, 5, 6491

Received 22nd March 2013

Accepted 10th May 2013

DOI: $10.1039 / c 3 n r 01432 k$

www.rsc.org/nanoscale

\section{Carbon nanotube-gold nanohybrids for selective catalytic oxidation of alcohols $\uparrow$}

\author{
Rahul Kumar, ${ }^{\text {ab }}$ Edmond Gravel, ${ }^{a}$ Agnès Hagège, ${ }^{\text {cd }}$ Haiyan Li, ${ }^{\text {e }}$ Dhanaji V. Jawale, ${ }^{a}$ \\ Deepti Verma, ${ }^{b}$ Irishi N. N. Namboothiri ${ }^{* b}$ and Eric Doris ${ }^{* a}$
}

Gold nanoparticles were deposited on carbon nanotubes to provide access to a nanohybrid structure which was involved in the aerobic oxidation of alcohols. The nanohybrid-catalyzed reaction was shown to be highly efficient under mild conditions (i.e. room temperature, air) and selective oxidation of alcohols to the corresponding acids or aldehydes could be achieved, depending on the reaction conditions.

\section{Introduction}

The chemoselective oxidation of alcohols is one of the key transformations in organic synthesis. While stoichiometric amounts of oxidizing reagents and harsh conditions are classically required to perform alcohol oxidation, ${ }^{1}$ recent developments have led to the discovery of highly active heterogeneous catalytic systems. Among these, supported metal nanoparticles have gained increasing interest as they provide clean, selective, and efficient reactions. ${ }^{2}$ In addition, these nanoparticulate catalysts can be easily recovered, thus permitting their reuse. Numerous metals, ${ }^{3}$ including gold, ${ }^{4}$ have been assembled onto solid supports although metallic gold has traditionally been regarded as a poor catalytic species. ${ }^{5}$ The catalytic activity of bulk gold is nevertheless dramatically enhanced when downsized to nanometric particles (AuNPs). ${ }^{6-8}$ This peculiar behaviour of nano-gold has recently boosted its use in fine chemical synthesis applied, for example, to selective hydrogenations, carbon-carbon bond formation, or oxidations. ${ }^{9-12}$ We recently contributed to the field of carbon nanotube (CNT) supported AuNPs $^{13}$ and nano-gold catalyzed reactions by reporting one of the most efficient systems for silane oxidation. The system used molecular oxygen and water as oxidant sources in combination with carbon nanotube-gold nanohybrids (AuCNT, Fig. 1). ${ }^{14}$ When compared to other supports, CNTs

${ }^{a}$ CEA, iBiTecS, Service de Chimie Bioorganique et de Marquage, 91191 Gif-sur-Yvette, France. E-mail: eric.doris@cea.fr; Fax: +33 16908 79 91; Tel: +33 169088071

${ }^{b}$ Department of Chemistry, Indian Institute of Technology Bombay, Mumbai 400 076, India.E-mail: irishi@chem.iitb.ac.in

${ }^{c} C E A$, iBEB, Service de Biochimie et de Toxicologie Nucléaire, 30207 Bagnols-sur-Cèze, France

${ }^{d} C E A$, iBEB, CNRS-UMR 7265, 13108 Saint Paul-les-Durance, France

${ }^{e}$ State Key Laboratory of Physical Chemistry for Solid Surfaces and National Engineering Laboratory for Green Chemical Productions of Alcohols, Ethers, and Esters, Department of Chemistry, College of Chemistry and Chemical Engineering, Xiamen University, Xiamen 361005, China

$\dagger$ Electronic supplementary information (ESI) available: Detailed synthetic procedures and supplementary figures. See DOI: $10.1039 / \mathrm{c} 3 \mathrm{nr} 01432 \mathrm{k}$ offer some advantages that include chemical, thermal and mechanical stability, inertness (i.e. little to no interactions with the catalyzed organic transformation), high surface area, and chemically tuneable topography. Moreover, CNTs are

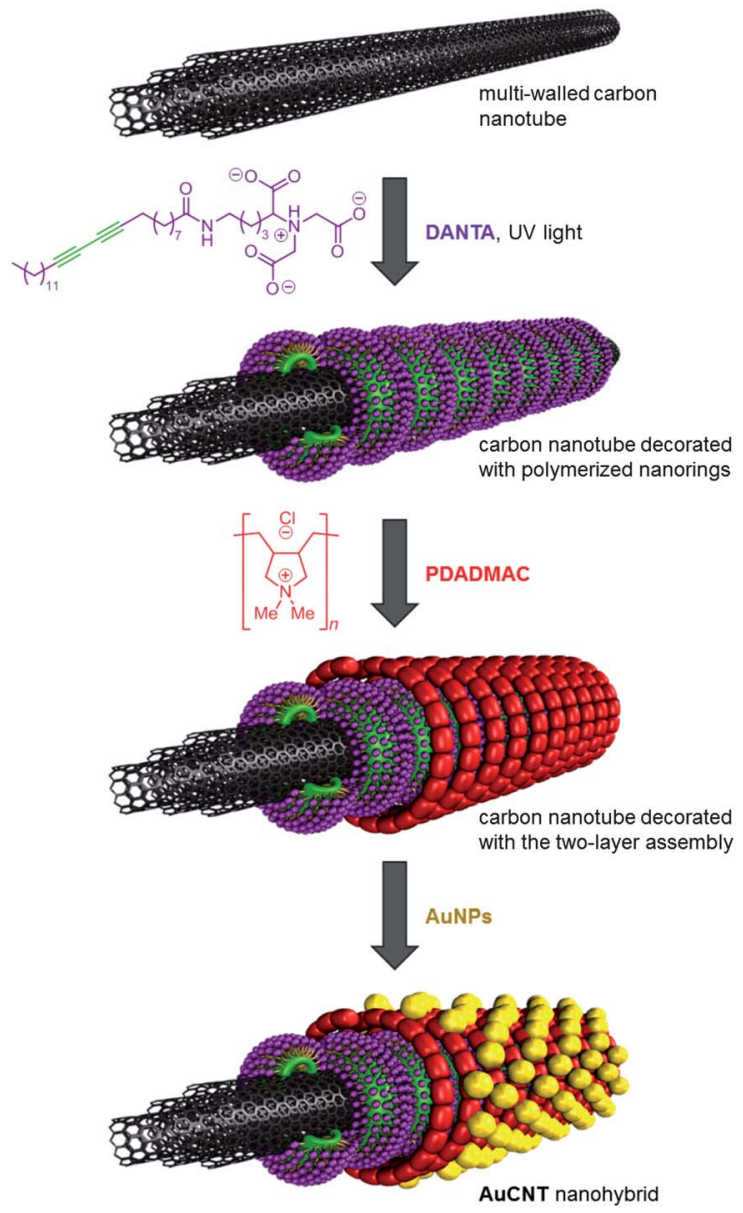

Fig. 1 Synthesis of the AuCNT assembly. 
electronically active and can contribute to the stabilization of transient higher oxidation states of the metals. In this article, we report our investigations on the selective oxidation of alcohols catalyzed by our original AuCNT nanohybrid.

\section{Experimental}

\section{General}

Chemicals were purchased from Sigma-Aldrich except $\mathrm{H}_{2}{ }^{18} \mathrm{O}$ that was obtained from Euriso-top (Saclay, France). $N^{6}$-Pentacosa-10,12-diynoyl- $N^{2}, N^{2}$-bis(carboxymethyl)lysine (DANTA) was synthesized as previously described. ${ }^{\mathbf{1 4}}$ Multi-walled carbon nanotubes (MWCNTs) were prepared by catalytic decomposition of methane on a Ni-Mg-O catalyst. ${ }^{\mathbf{1 4}}$ Flash chromatography was carried out on a Kieselgel 60 (230-240 mesh, Merck). Electron microscopy observations were carried out on a Philips CM12 microscope operated at $100 \mathrm{kV}$. NMR spectra were recorded on a Bruker Avance DPX 400 spectrometer. Chemical shifts $(\delta)$ are given in ppm relative to the NMR solvent residual peak and coupling constants $(J)$ in hertz.

\section{Nanohybrid synthesis and characterization}

Self-assembly and polymerization of the amphiphile on the CNTs. Amphiphilic diacetylenic nitrilotriacetic lipid (DANTA, $20 \mathrm{mg}$ ) was dissolved in an aqueous Tris buffer ( $2 \mathrm{~mL}, \mathrm{pH}$ 8) before CNTs $(50 \mathrm{mg}$ ) were added. After $10 \mathrm{~min}$ of sonication with an ultra-sonic probe ( $5 \mathrm{~min}, 300 \mathrm{~ms}$ pulses per second, $25 \mathrm{~W}$ output power), a stable suspension was recovered and centrifuged at $5000 \times g$ for 3 min to remove amorphous carbon. The supernatant was collected and centrifuged at $11000 \times g$ for $45 \mathrm{~min}$ to separate the DANTA-decorated nanotubes from the excess of the amphiphile. The pellet was resuspended in a fresh buffer and centrifuged again at $11000 \times g$ for $45 \mathrm{~min}$. The final pellet was resuspended in the buffer and submitted to UV irradiation $(254 \mathrm{~nm})$ for $8 \mathrm{~h}$ to polymerize the diacetylene groups and stabilize nanoring assemblies.

Assembly of the second layer on the nanoring-coated nanotubes. After polymerization, the CNT suspension was stirred in the presence of cationic poly(diallyldimethylammonium chloride) (PDADMAC, $700 \mu \mathrm{L}$ of a $20 \%$ solution in $\mathrm{H}_{2} \mathrm{O}$ ) for $1 \mathrm{~h}$ to induce the formation of the two-layer assembly. The excess of the polymer was removed by centrifugation at $11000 \times g$ for 30 min and the pellet was resuspended in a Tris buffer. This operation was repeated twice with the Tris buffer and two more times with pure water. The final pellet was resuspended in $1 \mathrm{~mL}$ of water.

Assembly of gold nanoparticles. Freshly prepared gold nanoparticles ${ }^{\mathbf{1 5}}$ (1 $\mathrm{mM}$ colloid suspension) were added to the doubly coated CNTs and the mixture was left at RT with $1 \mathrm{~min}$ vortex-stirring every $30 \mathrm{~min}(4 \mathrm{~h})$. The suspension was then centrifuged at $3000 \times g$ for $5 \mathrm{~min}$ and the nearly colorless supernatant was discarded and replaced with a fresh gold colloid suspension. The same process was repeated 5 times to ensure optimal loading of the tubes with AuNPs. The obtained pellet ( $c a .30 \mathrm{mg}$ of the dry material) was washed 3 times by centrifugation/redispersion in water and finally redispersed in
$4 \mathrm{~mL}$ of water to yield the AuCNT suspension that was used for all catalysis experiments.

Characterization and loading measurement of AuCNT nanohybrids. The hybrids were characterized by transmission electron microscopy (TEM) to observe the morphology of the assemblies and measure the mean particle size; X-ray photoelectron spectroscopy (XPS) was used to confirm that only metallic gold was present in the hybrids; inductively coupled plasma mass spectrometry (ICP-MS) was used to measure the gold content of the suspension.

\section{General procedure for the oxidation of alcohols and aldehydes}

To a stirred solution of an alcohol/aldehyde $(0.1 \mathrm{mmol})$ in a 1 : 1 mixture of toluene-water $(0.5 \mathrm{~mL})$ was added $\mathrm{NaOH}(0.3$ $\mathrm{mmol})$ and aqueous AuCNT $(50 \mu \mathrm{L}, 0.2 \mathrm{~mol} \%)$. The reaction mixture was stirred until the complete consumption of the starting material (as monitored by TLC). After the completion of the reaction the aqueous phase was washed with $\mathrm{Et}_{2} \mathrm{O}(2 \times$ $5 \mathrm{~mL})$, acidified with $1 \mathrm{~N} \mathrm{HCl}(1 \mathrm{~mL})$ and extracted with EtOAc $(3 \times 5 \mathrm{~mL})$. The combined organic layers were dried over $\mathrm{Na}_{2} \mathrm{SO}_{4}$, filtered, and concentrated under a vacuum to afford the expected acid. For secondary alcohols, no acidic work up was needed and the aqueous layer was directly extracted with EtOAc.

\section{Results and discussion}

\section{Synthesis of AuCNT hybrids}

The carbon nanotube-gold nanohybrid catalyst was prepared by self-assembly of amphiphilic nitrilotriacetic-diyne lipid (DANTA) on carbon nanotubes (Fig. 1). This led to the formation of hemi-micelles with nanoring-like structures (Fig. 1). ${ }^{\mathbf{1 4}, \mathbf{1 6 - 1 8}}$ While the hydrophobic portion of DANTA is adsorbed on CNT by van der Waals interactions, its hydrophilic head is oriented toward the aqueous phase. Further stability of the rings was promoted by photo-polymerization at $254 \mathrm{~nm}$ of the diyne motif incorporated in the lipophilic chain. This polymerization process takes place within individual half-cylinders and reinforces the cohesion of the assembly. ${ }^{19}$ The second layer was thereafter deposited by stirring the suspended nanotubes with cationic PDADMAC which adsorbed on the tube surface by electrostatic interactions with the primary anionic layer. A solution of freshly prepared colloidal gold nanoparticles ${ }^{\mathbf{1 5}}$ was then added to the doubly coated CNTs. Interaction of AuNPs with polyammonium-covered nanotubes afforded the final AuCNT nanohybrid assembly. Transmission electron microscopy showed nanotubes fully decorated with dense and uniform coating of monodisperse AuNPs (Fig. 2). Size evaluation by statistical diameter measurement indicated a mean particle diameter of $c a .3 \mathrm{~nm}$. XPS analysis (see ESI, Fig. S1†) showed only the presence of metallic gold in the nanohybrid sample. The AuCNT catalyst was suspended in water and used as such in the oxidation of alcohols.

The gold content in the aqueous suspension of the nanohybrid was measured by ICP-MS which indicated a gold concentration of $4 \mathrm{mM}$. 


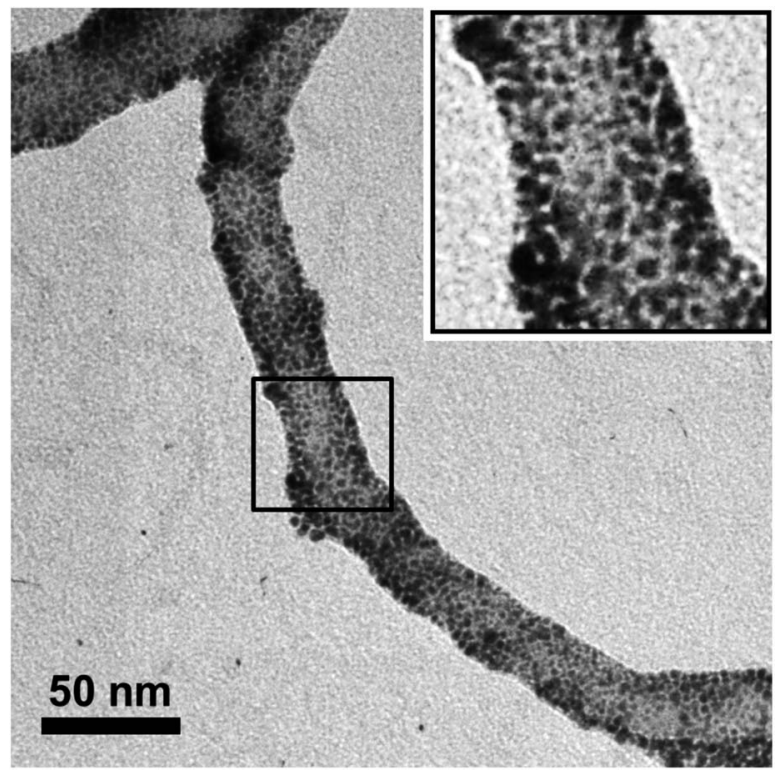

Fig. 2 TEM picture of the AuCNT hybrid. The inset is a $250 \%$ magnification of the selected area.

\section{Catalytic oxidation of alcohols using AuCNT}

The catalytic activity of the nanohybrid in the aerobic oxidation of alcohols was then assessed using benzyl alcohol as a model substrate. Our primary objective was to develop a catalytic system that would be effective under the mildest and less constraining conditions ${ }^{\mathbf{2 0 - 2 7}}$ since analogous supported gold catalyzed transformations usually require drastic conditions such as heating and/or oxygen pressure..$^{28-35}$ Numerous reaction conditions were tested by varying the nature of the solvent (THF, toluene, water), base $\left(\mathrm{K}_{2} \mathrm{CO}_{3}, \mathrm{DBU}, \mathrm{LiOH}, \mathrm{NaOH}\right)$, and catalyst loading. We found that the optimal conditions in terms of conversion yield and reaction time were obtained using a biphasic toluene-water mixture, $0.2 \mathrm{~mol} \%$ of AuCNT, and 3 equivalents of $\mathrm{NaOH}$. More importantly, the reaction was run at room temperature and under atmospheric pressure of air (open flask). Under the above conditions, benzyl alcohol (1a) was cleanly converted to benzoic acid (2a) in 99\% yield after $3 \mathrm{~h}$ (Scheme 1). The turnover number (TON) and turnover frequency (TOF) calculated from this experiment were 495 and $165 \mathrm{~h}^{-1}$, respectively. Although less efficient than gold-based bimetallic species (e.g. $\mathrm{Au}-\mathrm{Pd}^{36}$ or $\left.\mathrm{Au}-\mathrm{Pt}^{37}\right)$ the values obtained for our AuCNT catalyst compare favorably with most of the other nano-gold systems reported in the literature ${ }^{38}$ (for a detailed comparison, see Table $\mathrm{S} 1$ in the ESI $\dagger$ ). If the kinetic values were to be calculated by taking into account only the

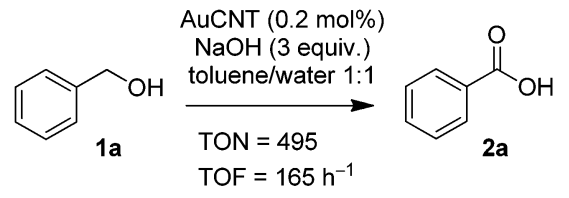

Scheme 1 Oxidation of benzyl alcohol with AuCNT. gold-surface atoms (those in contact with the medium) and not the actual Au loading (total gold content), more flattering TOF and TON values for benzyl alcohol oxidation would be reached $\left(\mathrm{TON}=1648\right.$, TOF $\left.=549 \mathrm{~h}^{-1}\right)$.

To highlight the superiority of CNT-supported AuNPs over other gold sources, the oxidation of benzyl alcohol to benzoic acid was also run with the same amount ( $0.2 \mathrm{~mol} \%)$ of colloidal AuNPs or gold salts. However, colloidal gold NPs provided only partial conversion (15\%) of benzyl alcohol after $3 \mathrm{~h}$, and gold salts did not promote any formation of benzoic acid even after 5 days of reaction (Table 1). An additional control experiment was performed using the nanoassembly devoid of AuNPs (i.e. CNT/ DANTA/PDADMAC only) which showed no activity in the oxidation of benzyl alcohol, even after several days. These results have to be compared to the nearly quantitative conversion of benzyl alcohol in $3 \mathrm{~h}$ by the AuCNT nanohybrid.

\section{Recyclability and heterogeneous nature of the catalyst}

Recyclability of the catalyst was evaluated by performing five consecutive oxidation reactions using the same AuCNT hybrid which could be recovered by simple filtration. No drastic decrease in activity was observed throughout the experiments (Table 2) although higher reaction times (i.e. $5 \mathrm{~h}$ ) were required for the third and fourth recyclings. The latter point suggests that some leaching of gold nanoparticles from the nanotube surface had taken place. This phenomenon could lead to an overall reduction in gold content and therefore to a "slower" catalyst. TEM analysis of the hybrid after the fourth run confirmed the partial loss of some gold nanoparticles as a few nanotubes with bare areas were detected by electron microscopy.

To confirm the key role of the AuCNT nanohybrid as the active catalytic species, a standard oxidation reaction of benzyl alcohol was set up using $0.2 \mathrm{~mol} \%$ of the catalyst. After $1 \mathrm{~h}$,

Table 1 Comparison of different gold sources to catalyze the conversion of $\mathbf{1 a}$ to $2 a^{a}$

\begin{tabular}{lll}
\hline Entry & Catalyst & Reaction outcome \\
\hline 1 & AuCNT & $>99 \%$ conversion $(3 \mathrm{~h})$ \\
2 & Colloidal AuNPs & $15 \%$ conversion $(3 \mathrm{~h})$ \\
3 & $\mathrm{HAuCl}_{4}$ & No reaction $(5$ days $)$
\end{tabular}

${ }^{a}$ Conditions: $1 \mathrm{a}(0.1 \mathrm{mmol})$, gold catalyst (0.2 mol\%), toluene-water 1 : 1 (1 mL), NaOH (3 equiv.), room temp., open flask (air).

Table 2 Recycling of AuCNT for the conversion of $\mathbf{1 a}$ to $\mathbf{2} \mathbf{a}^{a}$

\begin{tabular}{llll}
\hline Entry & Cycle & Time $(\mathrm{h})$ & Yield $^{b}(\%)$ \\
\hline 1 & Fresh & 3 & 99 \\
2 & $1^{\text {st }}$ recycle & 3 & 99 \\
3 & $2^{\text {nd }}$ recycle & 3 & 97 \\
4 & $3^{\text {rd }}$ recycle & 5 & 98 \\
5 & $4^{\text {th }}$ recycle & 5 & 98
\end{tabular}

${ }^{a}$ Conditions: 1a (0.1 mmol), AuCNT (0.2 mol\%), toluene-water $1: 1$ (1 $\mathrm{mL}$ ), $\mathrm{NaOH}$ (3 equiv.), room temp., open flask (air). ${ }^{b}$ Isolated yields. 
approximately $50 \%$ conversion into benzoic acid was reached. At this stage, the supported catalyst was removed by filtration, and the catalyst-free mixture was further stirred overnight at room temperature. However, no additional oxidation of benzyl alcohol was observed, thus confirming the heterogeneous nature of the catalytic process.

\section{Scope and conditions of the AuCNT-catalyzed reaction}

Primary alcohols. We first investigated the scope of the reaction by screening variously substituted primary alcohols. The reaction was successfully extended to aromatic alcohols bearing electron donating (1b, Table 3, entry 2) or withdrawing substituents (1c and 1d, entries 3 and 4). In both cases the expected oxidized products were produced in good to excellent yields with no significant changes in the kinetics of the oxidation, as the reaction was completed within 3 h. Naphthyl-1methanol (1e, entry 5), indole-3-carbinol (1f, entry 6), and conjugated cinnamyl alcohol (19, entry 7) were also efficiently oxidized into their corresponding acids but $4 \mathrm{~h}$ were needed for completion of the reaction in the case of the substrate $\mathbf{1 f}$. Although highly efficient on aromatic substrates, the nanohybrid-mediated oxidation was not successful on aliphatic alcohols as no significant conversion of 2-phenyl-ethanol (1h, entry 8) or 1-octanol (1i, entry 9) was observed after $72 \mathrm{~h}$ of reaction. It should be noted that carboxylated products were readily purified by a simple acid/base workup.

Secondary alcohols. To further extend the scope of the reaction, secondary alcohols were studied under similar conditions. For instance, 1-phenylethanol (3a) was converted to

Table 3 AuCNT-catalyzed oxidation of primary alcohols ${ }^{a}$

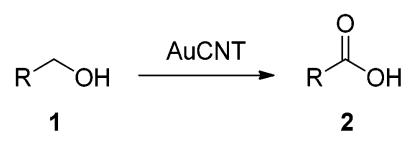

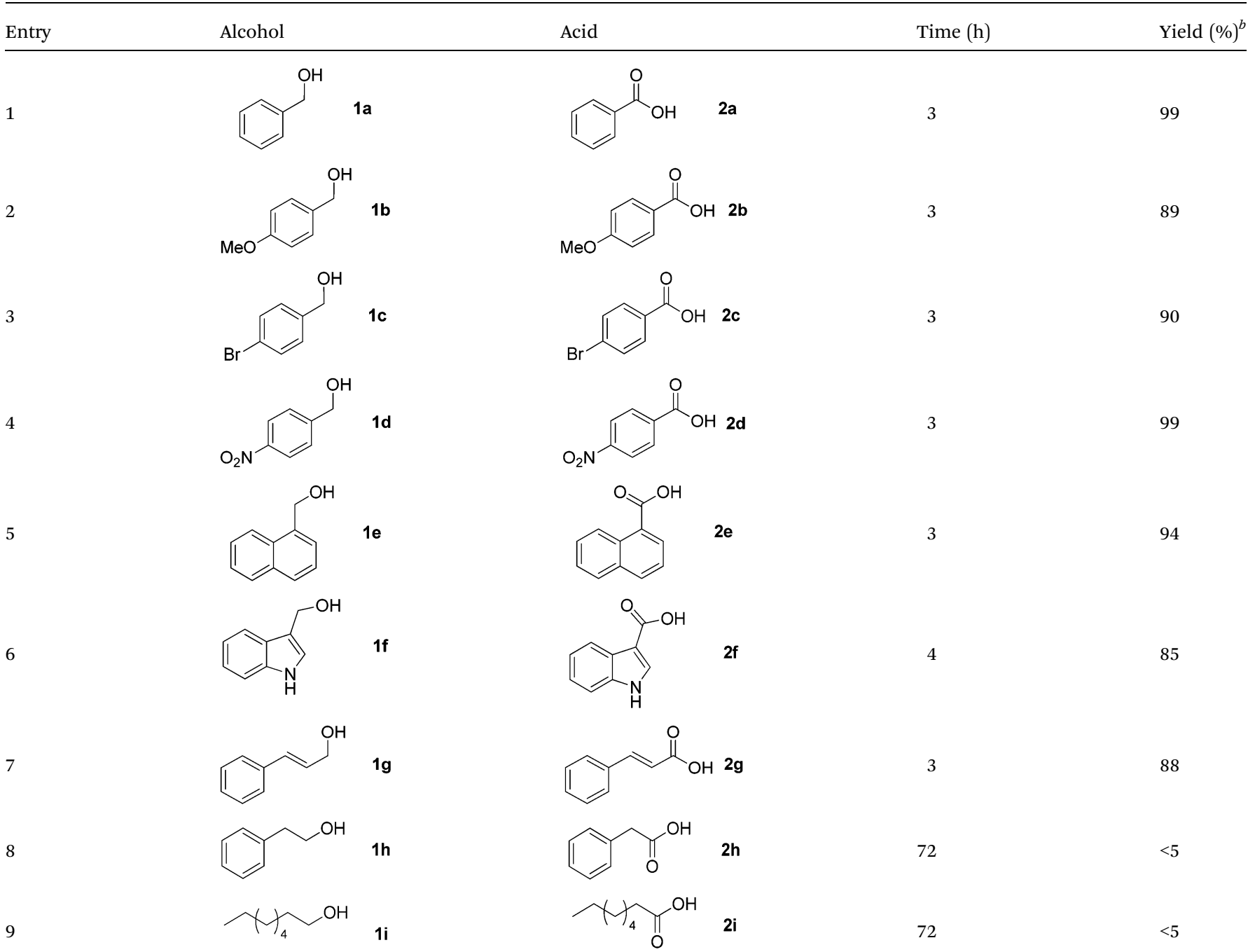

\footnotetext{
${ }^{a}$ Conditions: 1 (0.1 mmol), AuCNT (0.2 mol\%), toluene-water $1: 1(1 \mathrm{~mL}), \mathrm{NaOH}$ (3 equiv.), room temp., open flask (air). ${ }^{b}$ Isolated yields.
} 
Table 4 AuCNT-catalyzed oxidation of secondary alcohols ${ }^{a}$

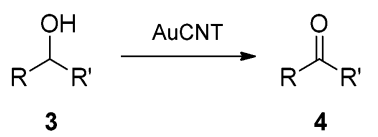

${ }^{a}$ Conditions: $\mathbf{1}(0.1 \mathrm{mmol}), \mathrm{AuCNT}(0.2 \mathrm{~mol} \%)$, toluene-water $1: 1$ (1

acetophenone (4a) in $80 \%$ yield after $24 \mathrm{~h}$ of reaction (Table 4 , entry 1). Secondary alcohols bearing sterically hindered groups, such as $\mathbf{3 b}$, 3c, and $\mathbf{3 d}$ (entries 2, 3 and 4), were also readily oxidized in high yields into the corresponding ketones $\mathbf{4 b}, \mathbf{4 c}$, and 4d, respectively. Surprisingly, the reaction of 1-phenylethane-1,2diol (3e, entry 5) under the same reaction conditions did not afford the expected ketone but led to the oxidative cleavage of the 1,2-diol unit to provide clean access to benzoic acid. $\$$

Reaction conditions. Interestingly, no reaction occurred under an inert atmosphere of $\mathrm{N}_{2}$ with either primary or secondary alcohols, suggesting that molecular oxygen was needed as an activator. The same comment applies to the use of a hydroxylated base which is mandatory for the reaction to evolve. Moreover, when water was depleted from the reaction mixture, alcohol oxidation stopped at the intermediate aldehyde stage. For example, in the absence of water, benzaldehyde was produced quantitatively in $12 \mathrm{~h}$ starting from benzyl alcohol (Scheme 2). Upon addition of $\mathrm{H}_{2} \mathrm{O}$ to the reaction mixture, benzaldehyde (5a) got further oxidized into benzoic acid within $2 \mathrm{~h}$ and in $99 \%$ yield. Our catalytic system thus behaves selectively depending on the reaction conditions.

Oxidation of aldehydes. As benzaldehyde could be readily converted into the corresponding carboxylic acid, we next

\$ This reaction likely involves phenyl glyoxalic acid as the intermediate as treatment of authentic phenyl glyoxalic acid with the AuCNT nanohybrid under classical reaction conditions (biphasic mixture, air, room temp., $\mathrm{NaOH}$ ) also cleanly provided access to benzoic acid.

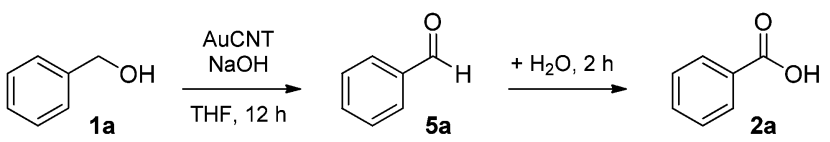

Scheme 2 Chemoselective oxidation of benzyl alcohol.

turned our attention to the AuCNT-catalyzed oxidation of various aldehydes. When the oxidation was conducted with authentic benzaldehyde (5a), the reaction was completed in just $2 \mathrm{~h}$ in nearly quantitative yield (Table 5, entry 1 ). Interestingly, the nanohybrid-catalyzed oxidation of aliphatic octan-1-al (5i) afforded octanoic acid (2i) in satisfactory yield (entry 2). This result points out that the alcohol to aldehyde transformation is likely the rate determining step as the previous reaction of aliphatic alcohols was found to be lethargic (vide supra). Additionally, dialdehyde $\mathbf{5 j}$ (entry 3 ) and heteroaryl aldehyde $\mathbf{5 k}$ (entry 4) were also screened with regard to aerobic oxidation and afforded the corresponding acids in $85 \%$ and $78 \%$ yield, respectively, after $2 \mathrm{~h}$. Under the above conditions, glucose (5l) was also smoothly oxidized to gluconic acid (2l, entry 5) in excellent yield in just $3 \mathrm{~h}$.

\section{Role played by water and oxidation mechanism}

To elucidate the role of water in the oxidative process and assign the origin of the oxygen atom incorporated in the carboxylic group, an AuCNT oxidation reaction of benzyl alcohol was set up by replacing $\mathrm{H}_{2} \mathrm{O}$ by ${ }^{18} \mathrm{O}$-labeled water (Scheme 3). Benzoic 
Table 5 AuCNT-catalyzed oxidation of aldehydes ${ }^{a}$

Entry

${ }^{a}$ Conditions: 1 (0.1 mmol), AuCNT (0.2 mol\%), toluene-water $1: 1$ (1 mL), NaOH (3 equiv.), room temp., open flask (air). ${ }^{b}$ Isolated yields. ${ }^{c}$ AuCNT (0.4 mol\%), $\mathrm{NaOH}$ (6 equiv.). ${ }^{d}$ NMR yield.

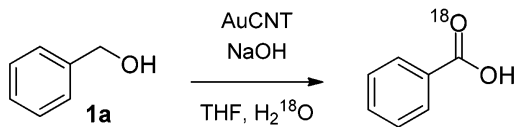

Scheme $3{ }^{18} \mathrm{O}$-labeling experiment to explore the role of water.

acid was recovered after $3 \mathrm{~h}$ and mass spectra analysis indicated that the carboxylic acid was labeled with one ${ }^{18} \mathrm{O}$ atom $(80 \%$ isotopic enrichment). To confirm that ${ }^{18} \mathrm{O}$ incorporation did take place during the oxidation process and not by exchange of oxygen atoms between the newly formed acid and $\mathrm{H}_{2}{ }^{18} \mathrm{O}$, a control experiment was performed. Non-labeled benzoic acid was stirred with $\mathrm{H}_{2}{ }^{18} \mathrm{O}$ under the above conditions. The solution was stirred at room temperature for $3 \mathrm{~h}$ after which the product was recovered and analyzed by mass spectrometry which indicated that no oxygen exchange had taken place. This experiment thus designates water as the prominent oxygen source.

Based on previous reports, ${ }^{39}$ alcohol oxidation over CNTsupported AuNPs proceeds by means of an aldehyde intermediate which gets further oxidized into the corresponding acid. Although not fully understood yet, one can suggest a plausible sequential mechanism for this transformation (Scheme 4): (i) the initial step is the deprotonation of the alcohol and the formation of a gold-alcoholate intermediate with concomitant adsorption of oxygen onto the gold surface which produces a transient hydroperoxide. This step is followed by (ii) the sodium hydroxide-mediated dehydrogenation of the activated alcohol into the corresponding aldehyde with the departure of hydrogen peroxide. In the presence of both water and sodium hydroxide, (iii) hydration of the newly formed aldehyde takes

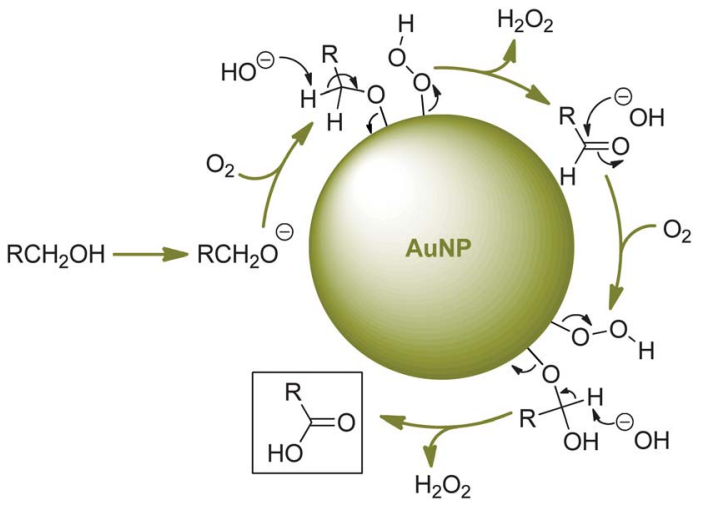

Scheme 4 Proposed mechanism for the oxidation of primary alcohols.

place, and finally, (iv) reiteration of steps (i) and (ii) on the hydrate intermediate ultimately delivers the expected carboxylic acid. As demonstrated above, oxygen incorporation originated from water but not from $\mathrm{O}_{2}$. The exact nature of the catalytic sites remains unclear although it has been investigated on related systems by others. ${ }^{40}$

\section{Conclusion}

In conclusion, we have shown that the CNT-supported gold nanohybrid is a promising catalyst for the aerobic oxidation of diversified alcohols under very mild conditions. The reported system is effective without any added $\mathrm{O}_{2}$ and requires no heating. While alcohols and aldehydes were chemoselectively oxidized to the corresponding acids, under anhydrous conditions, primary alcohols could also be converted to the 
corresponding aldehydes. Finally, the role of water in the oxidation process was elucidated using ${ }^{18} \mathrm{O}$-labeled water. Our CNT-based system compares favorably to other supported gold nanoparticles in terms of recyclability, catalytic activity, selectivity, and mildness of the operating conditions with regard to the oxidation of alcohols.

\section{Acknowledgements}

Support from the Indo-French Centre for the Promotion of Advanced Research (IFCPAR)/Centre Franco-Indien pour la Promotion de la Recherche Avancée (CEFIPRA) is gratefully acknowledged. R. K. thanks the French Embassy in India for the award of a Charpak fellowship. The International Relations Division (DRI) of the CEA is also acknowledged for support. We thank the TEM-team platform of the CEA for transmission electron microscopy pictures. The "Service de Chimie Bioorganique et de Marquage" belongs to the Laboratory of Excellence in Research on Medication and Innovative Therapeutics (LabEx LERMIT).

\section{Notes and references}

1 M. B. Smith and J. March, in March's Advanced Organic Chemistry, Wiley-Interscience, New York, 5th edn, 2001, pp. 1514-1518 and p. 1537.

2 For example, see: K. Mori, T. Hara, T. Mizugaki, K. Ebitani and K. Kaneda, J. Am. Chem. Soc., 2004, 126, 10657.

3 J. John, E. Gravel, I. N. N. Namboothiri and E. Doris, Nanotechnol. Rev., 2012, 1, 515.

4 M. Stratakis and H. Garcia, Chem. Rev., 2012, 112, 4469.

5 B. Hvolbæk, T. V. W. Janssens, B. S. Clausen, H. Falsig, C. H. Christensen and J. K. Nørskov, Nano Today, 2007, 2, 14.

6 A. S. K. Hashmi and G. J. Hutchings, Angew. Chem., Int. Ed., 2006, 45, 7896.

7 A. Corma and H. Garcia, Chem. Soc. Rev., 2008, 37, 2096.

8 Y. Mikami, A. Dhakshinamoorthy, M. Alvaro and H. García, Catal. Sci. Technol., 2013, 3, 58.

9 C. Della Pina, E. Falletta, L. Prati and M. Rossi, Chem. Soc. Rev., 2008, 37, 2077.

10 Y.Zhang, X. Cui, F. Shi and Y. Deng, Chem. Rev., 2012, 112, 2467.

11 C. Della Pina, E. Falletta and M. Rossi, Chem. Soc. Rev., 2012, 41, 350 .

12 S. Carrettin, M. Carmen Blanco, A. Corma and A. S. K. Hashmi, Adv. Synth. Catal., 2006, 348, 1283.

13 E. Gravel, S. Foillard, H. B. Zhang, H. Li and E. Doris, Sci. China: Chem., 2010, 53, 2015.

14 J. John, E. Gravel, A. Hagège, H. Li, T. Gacoin and E. Doris, Angew. Chem., Int. Ed., 2011, 50, 7533.

15 D. G. Duff, A. Baiker and P. P. Edwards, Langmuir, 1993, 9, 2301.
16 C. Thauvin, S. Rickling, P. Schultz, H. Celia, S. Meunier and

C. Mioskowski, Nat. Nanotechnol., 2008, 3, 743.

17 C. Richard, F. Balavoine, P. Schultz, T. W. Ebbesen and

C. Mioskowski, Science, 2003, 300, 775.

18 N. Mackiewicz, G. Surendran, H. Remita, B. Keita, G. Zhang, L. Nadjo, A. Hagège, E. Doris and C. Mioskowski, J. Am. Chem. Soc., 2008, 130, 8110.

19 D. J. Ahn and J.-M. Kim, Acc. Chem. Res., 2008, 41, 805.

20 H. Miyamura, R. Matsubara, Y. Miyazaki and S. Kobayashi, Angew. Chem., Int. Ed., 2007, 46, 4151.

21 S. Kim, S. W. Bae, J. S. Lee and J. Park, Tetrahedron, 2009, 65, 1461. 22 T. Mitsudome, A. Noujima, T. Mizugaki, K. Jitsukawa and K. Kaneda, Adv. Synth. Catal., 2009, 351, 1890.

23 K. Kaneda, T. Mitsudome, T. Mizugaki and K. Jitsukawa, Molecules, 2010, 15, 8988.

24 Y. Yuan, N. Yan and P. J. Dyson, Inorg. Chem., 2011, 50, 11069.

25 H. Tsunoyama, H. Sakurai, Y. Negishi and T. Tsukuda, J. Am. Chem. Soc., 2005, 127, 9374.

26 S. Kanaoka, N. Yagi, Y. Fukuyama, S. Aoshima, H. Tsunoyama, T. Tsukuda and H. Sakurai, J. Am. Chem. Soc., 2007, 129, 12060.

27 M. Comotti, C. Della Pina, R. Matarrese and M. Rossi, Angew. Chem., Int. Ed., 2004, 43, 5812.

28 A. Abad, C. Almela, A. Corma and H. García, Tetrahedron, 2006, 62, 6666.

29 A. Abad, A. Corma and H. García, Pure Appl. Chem., 2007, 79, 1847.

30 N. Zheng and G. D. Stucky, Chem. Commun., 2007, 3862.

31 J. Yang, Y. Guan, T. Verhoeven, R. Santen, C. Li and E. J. M. Hensen, Green Chem., 2009, 11, 322.

32 W. Fang, Q. Zhang, J. Chen, W. Deng and Y. Wang, Chem. Commun., 2010, 46, 1547.

33 P. Liu, Y. Guan, R. A. Santen, C. Li and E. J. M. Hensen, Chem. Commun., 2011, 47, 11540.

34 N. Asao, N. Hatakeyama, Menggenbateer, T. Minato, E. Ito, M. H. Y. Kim, Y. Yamamoto, M. Chen, W. Zhang and A. Inoue, Chem. Commun., 2012, 48, 4540.

35 M. Alhumaimess, Z. Lin, W. Weng, N. Dimitratos, N. F. Dummer, S. H. Taylor, J. K. Bartley, C. J. Kiely and G. J. Hutchings, ChemSusChem, 2012, 5, 125.

36 D. I. Enache, J. K. Edwards, P. Landon, B. Solsona-Espriu, A. F. Carley, A. A. Herzing, M. Watanabe, C. J. Kiely, D. W. Knight and G. J. Hutchings, Science, 2006, 311, 362.

37 K. Kaizuka, H. Miyamura and S. Kobayashi, J. Am. Chem. Soc., 2010, 132, 15096.

38 S. E. Davis, M. S. Ide and R. J. Davis, Green Chem., 2013, 15, 17. 39 For example see: B. N. Zope, D. D. Hibbitts, M. Neurock and R. J. Davis, Science, 2010, 330, 74.

40 A. Abad, A. Corma and H. Garcia, Chem.-Eur. J., 2008, 14, 212. 